\title{
Percepções espaciais no romance Antes da liberdade de Julia Alvarez
}

Dionei Mathias (UFSM)*

http://orcid.org/0000-0001-8415-1460

\section{Resumo:}

Adotando o espaço como categoria de análise do romance Antes da liberdade de Julia Alvares, este artigo busca retomar, num primeiro momento, a discussão teórica do conceito de espaço, especialmente em sua problematização a partir da virada espacial. Na sequência, o foco recai sobre a percepção espacial da protagonista e o modo como esse espaço está atrelado a vigilância, violência e restrição de mobilidade. Publicado em 2002, a obra em estudo é narrada a partir da perspectiva de Anita, jovem de 12 anos. 0 leitor tem acesso a uma realidade ficcional que aborda a última etapa do regime ditatorial de Rafael Leonidas Trujillo na República Dominicana. 0 relato de Anita esboça espaços sociais caracterizados por vigilância, violência e restrição de mobilidade e discute como esses elementos impactam na construção da identidade de seus membros familiares.

Palavras-chave: Julia Alvarez; Antes da liberdade; espaço; identidade.

\section{Abstract:}

\section{Spatial Perceptions in Julia Alvarez' novel Before we were free}

This article adopts space as focus of analysis and tries to recover the theoretical discussion of the concept of space, especially in the approach following the spatial turn. Subsequently, the focus is on the protagonist's spatial perception and the way in which this space is linked to surveillance, violence and mobility restriction. Alvarez' novel was published in 2002 and is narrated from the perspective of a 12-year-old girl, called Anita. The reader has access to a fictional reality that addresses the last stage of Rafael Leonidas Trujillo's dictatorial regime in the Dominican Republic. Anita's account outlines social spaces characterized by surveillance, violence and restricted mobility and discusses how these elements have an impact on the construction of the identity of her family members.

Keywords: Julia Alvarez; Before we were free; space; identity.

* Professor do Departamento de Letras Estrangeiras Modernas e do Programa de Pós-Graduação em Letras da UFSM. E-mail: dioneimathias@gmail.com 


\section{Introdução}

Nascida em 1950, a escritora Julia Alvarez é hoje uma das vozes de maior reverberação da comunidade latina nos Estados Unidos. Em grande medida, seus textos abordam a intersecção de pertencimento entre a República Dominicana - a origem de sua família - e a existência nos Estados Unidos. Com produção ficcional extensa, a autora alcançou notoriedade com romances como How the García Girls Lost Their Accents e In the Time of the Butterflies, ambos publicados no início da década de noventa e com foco nas dimensões políticas que levaram muitos dominicanos a buscar refúgio em outros países. A produção literária de Julia Alvarez, portanto, inscreve-se na discussão da presença da comunidade hispânica nos Estados Unidos, como também na literatura de fluxos migratórios internacionais (MATHIAS, 2018).

0 romance Before we were free, de 2002, traduzido para o português por Sérgio Tellaroli com título de Antes da liberdade se insere na discussão sobre fluxos migratórios. 0 texto é narrado a partir da perspectiva de Anita de la Torre, que está perto de completar doze anos. Suas percepções e interpretações guiam o olhar do leitor, desvelando o envolvimento da família com questões políticas, durante o regime ditatorial do general Rafael Leonidas Trujillo. Nesse sentido, esse romance se insere numa produção literária que se dedica a encenar a perspectiva de crianças e jovens, cujos pais optam ou se veem obrigados a um deslocamento migratório. Nessa esteira, o romance de Julia Alvarez se junta a um coro de vozes ao lado de escritores como Oscar Hijuelos e Junot Díaz nos Estados Unidos (MATHIAS, 2021) e Hanif Kureishi no Reino Unido (MATHIAS, 2020), cujo interesse se volta aos impactos de fluxos migratórios e suas motivações para a formação identitária na infância e na virada para adolescência, formando um corpus literário importante para a contemporaneidade.

Como Junot Díaz, Julia Alvarez também se volta à República Dominica, esboçando um cenário social que explica as motivações para fluxos migratórios e as implicações inerentes a esse movimento. Muitos desses aspectos já foram analisados pela crítica. Assim, Matias-Ferreira (2012) discute questões identitárias que surgem do encontro entre duas socializações culturais no romance How the García Girls Lost Their Accents, enquanto Castro Ricalde (2005) problematiza o conceito de cultura com foco em elementos híbridos. Nesse mesmo horizonte, Albuquerque e Cordiviola (2017) se voltam à intersecção entre a condição de mulher e a situação política, no romance In the Times of the Butterflies, enquanto Medina (2010), por sua vez, aborda a dimensão histórica encenada nos romances de Alvarez. Nessa esteira, o romance Antes da liberdade se junta a esse conjunto ficcional para retratar o processo de deslocamento de um país acometido por um regime ditatorial em direção ao exílio nos Estados Unidos.

Antes do início da narrativa, o romance apresenta um mapa da vila onde mora a protagonista, detalhando o traçado de muros, limites, subdivisões. Esse mapa não só cartografa a vila onde moram a família e outros interlocutores próximos da protagonista, ele também revela algo sobre sua posição social. Anita pertence a uma classe social abastada, mora na mesma região onde ficam as residências de embaixadores e de familiares de Trujillo. Mais importante que o posicionamento na estrutura social 
da República Dominicana é a tentativa de cartografar o espaço e atribuir sentido aos elementos que formam as coordenadas de interação da jovem protagonista. 0 mapa, de certa forma, antecipa uma estratégia central do romance, isto é, o modo como a protagonista se apropria da realidade, buscando ou identificando elementos espaciais que revelem algo sobre seu lugar no mundo.

Para a virada espacial nos Estudos Culturais, o espaço tem um papel fundamental no processo de apropriação de realidade. Em sua introdução, Bachmann-Medick explica o deslocamento que o conceito de espaço sofreu:

Há muito, espaço não é visto mais como conceito físico-territorial, mas sim como relacional. Para a virada espacial, o espaço territorial como contêiner ou receptáculo não é determinante, mas sim o espaço como processo de produção social da percepção, do uso e da apropriação, muito estreitamente ligado ao plano simbólico da representação espacial (por exemplo, por meio de códigos, signos, mapas). Sobretudo, o entrelaçamento de espaço e poder se torna um eixo importante de análise (BACHMANN-MEDICK, 2006, p. 292) $)^{1}$.

No lugar de um cartografia que objetiva apreender o espaço como território, com coordenadas pelas quais o indivíduo transita, o foco passar a ser sua semântica, almejando entender como sentidos são atribuídos a determinadas dimensões da configu-

1 "Raum gilt also längst nicht mehr als physischterritorialer, sondern als relationaler Begriff. Für den spatial turn wird nicht der territoriale Raum als Container oder Behälter maßgeblich, sondern Raum als gesellschaftlicher Produktionsprozess der Wahrnehmung, Nutzung und Aneignung, eng verknüpft mit der symbolischen Ebene der Raumrepräsentation (etwa durch Codes, Zeichen, Karten). Vor allem aber wird die Verflechtung von Raum und Macht zu einer wichtigen Untersuchungsachse" (BACHMANNMEDICK, 2006, p. 292). ração espacial e como isso impacta no modo como o indivíduo se apropria do mundo. Assim, o interesse recai sobre formas de posicionamento, decorrentes de dinâmicas de poder e, com isso, de políticas de hierarquização. Isso significa que o processo de encenação do espaço na esfera ficcional sempre contém um movimento em que personagens procuram localizar a si e seus interlocutores, posicionando-os, mas também reagindo a posicionamentos que impactam em suas identidades. Em tal prisma, Hallet e Neumann discutem como a percepção espacial remonta a um esforço de processamento da realidade:

A encenação de espaço constitui um dos componentes fundamentais da apropriação (ficcional) de realidade. Em textos literários, espaço não é somente o lugar da ação, mas sempre também um portador cultural de sentido. Normas culturalmente dominantes, hierarquias de valor, imagens coletivas de centralidade e marginalidade, de próprio e de alheio assim como posicionamentos do indivíduo entre o conhecido e o desconhecido, em circulação, encontram no espaço uma manifestação concretamente explícita. Espaços no literatura, isso são espaços humanamente vivenciados nos quais confluem ocorrências espaciais, atribuição de sentido e modos individuais de experiência (HALLET; NEUMANN 2009, p. 11)².

2 "Die Raumdarstellung bildet eine der grundlegenden Komponenten der (fiktionalen) Wirklichkeitserschließung. Raum ist in literarischen Texten nicht nur Ort der Handlung, sondern stets auch kultureller Bedeutungsträger. Kulturell vorherrschende Normen, Werthierarchien, kursierende Kollektivvorstellungen von Zentralität und Marginalität, von Eigenem und Fremdem sowie Verortungen des Individuums zwischen Vertrautem und Fremden erfahren im Raum eine konkret anschauliche Manifestation. Räume in der Literatur, das sind menschlich erlebte Räume, in denen räumliche Gegebenheiten, kulturelle Bedeutungszuschreibungen und individuelle Erfahrungsweisen zusammenwirken“ (HALLET/NEUMANN, 2009, p. 11). 
No lugar de pensar o espaço como fronteiras e muros concretos ou como cartografias simplificadas do mundo, o que tem um papel central na literatura de fluxos migratórios, os críticos chamam atenção para a dimensão semântica e para o modo como espaços são formados num processo de gênese de sentido. Obviamente essa gênese também forma muros de separação e contenção, mas sua produção desestabiliza a cartografia territorial essencialista. Ela inclui dinâmicas de sentido em que o indivíduo se insere. Essa inserção nas dimensões espaciais ocorre no processo de socialização que tem início na família e se estende posteriormente a esferas sociais mais complexas. Ao interagir com outros atores sociais, o indivíduo vai se apropriando dos sentidos atribuídos aos espaços. Ao mesmo tempo, vai identificando a posição que lhe atribuída por seus interlocutores.

0 processo de construção identitária inclui, portanto, a internalização dos sentidos inerentes aos espaços em que o sujeito deseja ou é obrigado a transitar. Com base nessa internalização, surgem os modos individuais por meio dos quais cada indivíduo se apropria dessa realidade, produzindo subordinação às práticas instaladas, contestação ou resistência explícita. A partir desses diferentes vetores, a dinâmica inerente à percepção espacial é produzida no marco da manutenção, da alteração ou da negação. Nessa confluência, o sujeito produz o espaço ao semantizá-lo, mas o sujeito também é definido pelas malhas de sentido que já circulam e definem com atores sociais podem se posicionar nas respectivas coordenadas daquele espaço.

Com base nesse elo entre espaço e narrativa de identidade, este artigo se volta para o romance de Julia Alvarez, procurando refletir sobre duas percepções espaciais: es- paços marcados por vigilância e violência, num primeiro momento, bem como espaços e mobilidades, num segundo. Em ambos os casos, a protagonista Anita percebe o espaço e começa a compreender os sentidos que lhe são atribuídos, mas também suas implicações para seu posicionamento pessoal no mundo.

\section{Espaços de vigilância e violência}

0 contexto histórico no qual a realidade ficcional está ambientado é a fase final do regime ditatorial de Trujillo na República Dominicana, incluindo sua morte e o período de terror que se lhe segue. Com efeito, o pai e o tio de Anita se envolvem em movimentos de resistência, culminando com a notícia da morte do pai, que a família recebe já estando nos Estados Unidos. A partir da perspectiva de Anita, o leitor tem acesso ao espaço encenado, cujos sentidos, em grande parte, remontam à percepção da protagonista. Numa conversa com sua irmã Lucinda, Anita revela suas percepções:

Agora é que estou confusa mesmo. Pensei que gostássemos de El Jefe. Há uma fotografia dele pendurada na entrada de casa, com a legenda embaixo: TRUJILLO GOVERNA ESTA CASA. 'Mas se ele é tão ruim, por que a sra. Brown pôs a foto dele ao lado da de George Washington na sala de aula?'

'A gente tem de fazer isso. Como todo mundo. Ele é um ditador'.

Não sei bem o que um ditador faz. Mas essa não deve ser uma boa hora para perguntar (ALVAREZ, 2006, p. 34, grifos no original).

A interação com sua irmã mais velha encena como Anita procura compreender como o espaço em que ela transita está organizado, quais regras são adotadas pelos atores sociais que o instauram, de que maneira indivíduos devem se posicionar, a fim de coadunar suas ações com as expectativas 
dominantes. No lugar de obter essa clareza, Anita se vê confrontada com uma sensação de profunda confusão. Ela percebe que os sentidos que atribuíra até então a determinados elementos que formam a estrutura espacial se revelam equivocados, precisando atualizar sua semântica para compreender o modo como a família reage, diante das configurações narrativas inerentes a esse espaço.

Assim, os diferentes elementos que caracterizam a configuração espacial da casa como a foto do ditador e a narrativa que acompanha esse objeto precisam ser revisados, de modo que Anita alcance a interpretação espacial adotada pela família. $\mathrm{Na}$ verdade, até esse momento, ela não se dera conta de que o espaço da casa contém duas narrativas: uma versão que atende às expectativas externas de espaços políticos autoritários e violentos e outra versão que reflete o posicionamento dos familiares, no que diz respeito à discordância com narrativas a que se veem obrigados a reproduzir. Essa ambivalência gera incerteza, de forma que Anita não sabe como administrar os sentidos que circulam em suas coordenadas espaciais.

Essa incerteza se intensifica ainda mais, ao encontrar a mesma estratégia de encenação espacial na escola americana em que estuda. Lá, ela encontra a mesma foto ao lado do primeiro presidente americano, o que sugere que o espaço escolar não diferencia os modos como esses dois representantes políticos entendem seu papel na sociedade. Sua dúvida tampouco é sanada, quando sua irmã explica a necessidade disso, utilizando o lexema "ditador". o que Anita não entende não é somente o escopo semântico inerente à utilização lexical, seu não entendimento se refere sobretudo a uma dimensão pragmática, isto é, de posicionamento espacial implícita a essa figura social. Em outras palavras, ela não compreende como esse ator social específico define a permanência no espaço e as narrativas que definem seus sentidos.

Ao contrário dos outros membros da família, que já compreenderam as dimensões semânticas inerentes à circulação em seu espaço identitário, Anita se encontra num processo de socialização, em que paulatinamente vai reconhecendo a existência de vigilância e violência, por trás de indícios espaciais. Isso também se explicita ao ouvir outras conversas e começar a tecer elos causais entre os comportamentos:

Minhas primas parecem se consolar com aquela notícia. Por um instante, me passa pela cabeça que a mami só disse aquilo para fazê-las se sentir melhor. Como quando ela diz à minha avó em Nueva York que o tio Toni está bem, só para que a mamita não se preocupe com meu tio ainda jovem, que não vemos há meses (ALVAREZ, 2006, p. 23, grifos no original).

Anita presencia a despedida de suas primas, que estão deixando a República Dominicana para morar nos Estados Unidos. A mãe de Anita parece sugerir que a separação é algo provisório. É nesse momento que ela atrela essa estratégia ao modo como mãe consola a avó que já se encontra no exílio. Sem compreender exatamente os motivos, a protagonista enxergar somente que diferentes membros de sua família se veem confrontados com limitações no trânsito espacial (as primas García, a avó e, sobretudo, o tio Toni). Nas interações da mãe, portanto, há o mesmo jogo de duplicidade que prevê formas de estar no espaço: por um lado a necessidade de proteger membros queridos das incursões da violência, modulando as informações para evitar inquietações desmesuradas, por outro lado, o conhecimento do estado de vigilância e suas implicações. A figura materna domina essas duas práticas 
de interação com o espaço e administra suas semânticas específicas. Anita, por sua vez, se encontra num processo de formação social, em que começa a treinar o olhar para compreender como o espaço está relacionado com experiências de vigilância e violência.

Essa percepção se vê intensificada quando gestores oficiais do espaço nacional se dirigem à sua casa. Nesse primeiro contato com o Serviço de Inteligência do país, a distribuição de papéis no espaço e o escopo de suas possibilidades de definição ainda permanecem ambíguos:

Quando entram pelo hall que dá para os quartos, minha mãe hesita. 'É só uma revista de rotina, doña', o chefão diz. E a mami dá um sorriso pálido, tentando mostrar que não tem nada a esconder.

No meu quarto, um sujeito levanta o babydoll que eu tinha deixado no chão, como se uma arma secreta pudesse estar escondida debaixo dele. Outro arranca as cobertas da cama, puxando-as bruscamente para trás. Seguro-me na mão gelada da mami, que aperta um pouco mais a minha (ALVAREZ, 2006, p. 29, grifos no original).

Novamente, enquanto a mãe reconhece o alcance das implicações relacionadas à presença da polícia secreta em sua casa, Anita está aprendendo como espaços são geridos. Na superfície, todos os atores sociais envolvidos buscam tecer uma narrativa da normalidade, sugerindo respeito e cortesia. 0 que, de fato, está ocorrendo, contudo, é a invasão do espaço privado, com motivação de perseguição política. 0 cuidado com que os agentes reviram objetos revela sua suspeita de que a família esteja envolvida em alguma forma de resistência, deixando vestígios em seu espaço privado. 0 grau de agência sobre o espaço se fragiliza para a família, na medida em que os agentes oficiais explicitam a dimensão do seu controle sobre a casa e sua configuração espacial. Com efeito, a família precisa apagar os vestígios espaciais que possam remeter a qualquer discordância do regime, criando portanto uma malha superficial que sugere consonância.

Anita, por sua vez, também vê seu espaço pessoal invadido. 0 modo como o agente interage com esse espaço indica que age de acordo com uma narrativa que difere daquela adotada por seus pais. A passagem mostra a forma como a protagonista percebe a hostilidade desmesurada. Ela enxerga que há atores sociais que detém o poder de adentrar seu quarto, podendo interagir com seus objetos, sem qualquer desvelo ou hesitação. Ao mesmo tempo, sua mãe traz indícios de desconforto, como o sorriso pálido e as mãos geladas, indicando por meio do corpo os significados daquela interação espacial. Anita ainda não consegue descodificar esses diferentes indícios, mas seu processo de socialização e as experiências atreladas a esse percurso treinam seu olhar.

Na segunda vez que a polícia secreta invade o espaço privado da família, o comportamento dos agentes deixa o marco da vigilância para explicitar seu potencial de violência. Anita percebe como o espaço passa a ser administrado:

Chucha e eu nos agarramos uma à outra e vemos os homens puxar gavetas e jogar minhas roupas no chão. Logo, outro bando de homens entra no quarto, empurrando minha mãe em sua camisola de dormir. 'Traidores!', gritam.

A mami corre em minha direção e me abraça tão apertado que posso ouvir seu coração em disparada na minha cabeça. Estou apavorada demais para chorar (ALVAREZ, 2006, p. 121).

No lugar da suposta cordialidade que ainda caracterizava a primeira abordagem da polícia secreta, esse episódio revela 
como agora a narrativa de gestão espacial é outra. Nessa esteira, o atributo "traidores" desencadeia outras formas de concretizar a interação com a semiótica espacial e com os atores sociais responsáveis por sua semântica. Anita enxerga a impotência de sua mãe, identificando que sua voz já não tem mais qualquer impacto no modo como o espaço privado pode ser concebido e inserido em suas narrativas identitárias. Por meio da gestão do espaço, Anita começa a compreender o que significa o cerceamento da liberdade individual.

\section{Espaço e mobilidade}

Ao mesmo tempo que Anita passa por um processo de socialização que a faz compreender a ausência de liberdade para ocupar o espaço em consonância com os próprios anseios e projetos identitários, ela também começa a identificar as restrições de mobilidade dentro dessas coordenadas. Num primeiro momento, o mapa que antecede a exposição de sua narrativa sugere orientação e oportunidades de deslocamento. 0 desenvolvimento da trama, contudo, parece mostrar justamente o contrário, pois os mapeamentos concretos e metafóricos utilizados pela protagonista para buscar orientação e definir seu posicionamento no espaço não fornecem as informações necessárias para que possa concretizar seus deslocamentos. Com efeito, começa a perceber que por trás das cartografias superficiais, há mapeamentos, de certa forma, invisíveis que definem como cada interlocutor pode interagir com a malha espacial e lhe atribuir sentido:

Depois da passagem de El Jefe, fico ainda algum tempo à janela, observando um cintilar cor de prata no céu. 0 vôo diário da Pan Am decola em direção aos Estados Unidos. As García partiram nesse vôo, assim como meus avós, meus tios, minhas tias e suas respectivas famílias; depois, Lucinda e Susie; e, por fim, alguns dias atrás, o Sam e a mãe dele (ALVAREZ, 2006, p. 109, grifos no original).

A direção do olhar para o céu primeiramente revela uma curiosidade, um anseio que Anita ainda não consegue verbalizar. Esse movimento é característico para seu processo de socialização, pois procura entender as implicações da semiótica espacial que se escondem sob a superfície. Nesse bojo, Anita começa a compreender que objetos e seus posicionamentos espaciais têm outras dimensões além daquelas imediatamente visíveis. Assim, o corpo cintilante que atravessa o espaço aéreo costarriquenho deixa de ser somente uma atração para romper a monotonia do cotidiano, passando a conter sentidos que antes não tinha importância. 0 avião representa o meio de transporte em direção a uma outra forma de interação espacial, deixando para trás a restrição de mobilidade inerente a um regime de vigilância e violência, para buscar um espaço em que o indivíduo tenha maiores chances de expressar seus anseios e satisfazer seus projetos identitários.

Anita percebe que muitas pessoas que lhe são queridas já deixaram o país de origem para tentar uma outra vida nos Estados Unidos. A mobilidade necessária para essa mudança, contudo, não é algo dado. Pelo contrário, com uma sensibilidade crescente, Anita se apercebe que essa mobilidade também é um recurso restrito, mais acessível ou completamente indisponível de acordo com a proximidade com os detentores de poder. A partir desse horizonte de limitação, ela também começa a vislumbrar a importância da mobilidade para a construção de identidade. Ao longo da narrativa, Anita se dá conta que alguns amigos e membros da família puderam 
deixar o país, outros não, permanecendo à mercê de práticas autoritaristas. 0 avião deixa de ser diversão, para se transformar num potencial de liberdade, uma liberdade que está atrelada, antes de mais nada, às possibilidades de mobilidade no espaço da concretização existencial.

Ao passo que ela começa a enxergar a restrição de mobilidade, ela também passa a identificar os silêncios que acompanham essas ações. Conectado com o avião e suas implicações mais profundas de sentido, encontram-se a ausência de explicações por parte dos adultos, com os quais convive. Em seu processo de socialização, Anita percebe que a família García recebe autorização para deixar o país, mas ainda não compreende como isso está atrelado a uma dinâmica maior de mobilidade espacial. 0 mesmo vale para seus familiares que já se encontram nos Estados Unidos. Ela identifica as estratégias da figura materna para não inquietar a avó, mas não consegue apreender o papel do espaço como elemento central para a concretização de identidades.

Essa oscilação entre duas narrativas e duas dinâmicas de sentido que surgem a partir dos potenciais de mobilidade se revela igualmente importante com a mudança do cônsul americano para a vila em que a família de Anita mora:

Minha mãe está bem mais calma depois da mudança dos Washburn para a vila. É bom ter a proteção especial do cônsul da casa ao lado, mas também o dinheiro a mais é muito bem-vindo. A Construcciones de la Torre não vai bem. Está tudo parado por causa do embargo, seja isso o que for. Estamos tendo de cortar despesas, vender os carros dos tios e a mobília da casa dos meus avós, de quando papito estava bem de vida. Digo a minha mãe que ela pode vender meus sapatos marrons de amarrar e os macacões antiquados de que eu não gosto. Mas ela sorri e responde que, no momento, ainda não será necessário fazer isso (ALVAREZ, 2006, p. 44, grifos no original).

Primeiramente, a chegada do cônsul para a vizinhança da família produz uma alteração do comportamento da mãe. Sua maior tranquilidade sugere a Anita que a proximidade da família americana possibilita outras formas de mobilidade do espaço, já que acompanhada de maior segurança e proteção. 0 representante consular insere com sua presença, portanto, elementos que modificam a escala de poder, impactando no modo como os representantes do regime interagem no espaço em que o cônsul se encontra. Essa modificação nas dinâmicas de deslocamento espacial se revela na forma como a figura materna passa a se comportar.

Um segundo elemento se refere à questão econômica. Dadas as restrições políticas, o negócio da família passa por momentos de crise, de modo que já não tem mais os mesmos recursos econômicos de outrora. Diante dessa limitação, a chegada da família americana contribui para estabilizar essa situação, tendo consequências também na mobilidade espacial. Os recursos econômicos, restringidos ou expandidos, definem, em certa medida, onde e como atores sociais podem participar de dinâmicas sociais e, assim, interagir com espaços. 0 capital econômico, vale lembrar, é o que permite que muitos membros da família possam ir ao exílio nos Estados Unidos e se manter nesse país ou também frequentar espaços de elite no país de origem e no exterior como a escola americana em que Anita estuda ou a universidade americana onde o pai completou seus estudos. Em todos esses momentos, os recursos econômicos têm papel de destaque para interagir com diferentes espaços, participar deles e construir identidades a partir de suas semióticas. A partir desse poten- 
cial de mobilidade, os indivíduos produzem sentidos importante para seu ser no mundo. Anita reconhece isso no modo como a mãe passa a estar no espaço.

Em diferentes situações, portanto, Anita se depara com a restrição de mobilidade e seu impacto para a apropriação espacial. Isso vale para os membros familiares que deixam o país, para a mudança do cônsul americano e suas implicações para a família, por fim, também para as atividades de resistência política de seu tio Toni:

0 tio Toni sempre se junta a nós nas refeições. Não que ele coma muita coisa. Às vezes, conta sobre o que aconteceu com ele nos últimos meses. Contou que o SIM invadiu uma de suas reuniões com amigos e que ele conseguiu escapar, mas que, em vez de voltar para casa e pôr a família em perigo, preferiu se esconder, alternando entre casas seguras, sem nunca poder dormir mais do que umas poucas horas por noite. Ele continua muito nervoso o tempo todo, assustando-se sempre que uma porta bate ou que Lorena derruba alguma bandeja no chão. Presta atenção em tudo, nota a urticária da Lucinda e as unhas roídas do Mundín. É una vergüenza, vive dizendo, o queixo visivelmente tenso, uma vergonha que as crianças já não possam ser crianças nesse país de tanto sofrimento (ALVAREZ, 2006, p. 74-75, grifos no original).

No lugar de conversas descontraídas à mesa, o tio relata as dificuldades inerentes a uma narrativa identitária que não está em consonância com a visão de mundo dos detentores de poder. Seu relato revela que nesse espaço nacional não há lugar para a diversidade de projetos de si, pelo contrário, espera-se docilidade e subordinação incondicional à narrativa oficial. Sua resistência, portanto, tem implicações para o modo como ele pode transitar nesse espaço, o que afeta direta ou indiretamente a família como um todo. Assim, também seu espaço privado é invadido por agentes do governo, forçando-o à fuga. Com a identificação de sua resistência, ele já não tem mais a possibilidade de fixar residência ou manter interações contínuas com a família. 0 espaço deixa de ser fonte de sentidos para a construção e manutenção da identidade, para se transformar em campo minado, com perigos ininterruptos à sua integridade física.

Com isso, a administração espacial e suas possibilidades de mobilidade produzem o apagamento de determinadas redes de sentido e impõem outras, de modo a forçar os atores sociais a se adaptar à modalidade dominante de concepção espacial. $\mathrm{Na}$ família de Anita, essa adaptação às imposições espaciais ocorre por meio da fuga e da ausência no caso do tio e por meio de sinais corporais no caso de outros membros como Mundín e Lucinda, que simbolizam a limitação da mobilidade através de reações somáticas. 0 medo que se espraia, assim que ruídos inesperados irrompem no espaço, mostra corpos em tensão, atentos às limitações de mobilidade. Nessas interações com os membros familiares e com suas reações, Anita aprender a olhar para o espaço e enxergar malhas de sentido que ela não identificava na superfície, treinando, com isso, outras formas de ler o espaço.

\section{Considerações finais}

A partir da perspectiva de Anita, o romance de Julia Alvarez encena formas da produção social da percepção espacial. Em suas interações com outras personagens e em seu esforço de decodificação das malhas semióticas que se encontram encobertas pela superfície, Anita aprende a ler o espaço. Esse percurso de letramento espacial começa com a internalização da semiótica dominante, passando por processos de revisão e identificação de ambiguidades que aca- 
bam por produzir novas narrativas. Nesse trabalho de mapeamento, Anita traça novas cartografias territoriais que revelam dimensões mais complexas, inerentes ao movimento de construção identitária.

Assim, o título Antes da liberdade já indica a importância do espaço e modo como atores sociais pode se mover. 0 espaço que Anita encontra antes de partir ao exílio é um espaço caracterizado por vigilância e pelo emprego de violência. Trata-se de duas estratégias centrais para suprimir toda forma de diversidade e dissonância que possa vir a questionar a narrativa dominante. Atrelado a esse ambiente de supressão da diferença, encontra-se a restrição de mobilidade, o que produz um espaço que determinados atores sociais não possam se apropriar do espaço em consonância com seus projetos de identidade. Em seu percurso, Anita começa a identificar essa realidade do espaço, num movimento em que se afasta paulatinamente de concepções internalizadas em direção a uma maior capacidade de diferenciação que lhe permite obter outras percepções espaciais.

\section{Referências}

ALBUQUERQUE, Thays Keylla de; CORDIVIOLA, Adolfo. Mulher e ditadura na América Latina: uma análise de En el tiempo de las mariposas, de Julia Alvarez. Fragmentum, n. 49, p. 49-68, 2017.
ALVAREZ, Julia. Antes da liberdade. Tradução de Sérgio Tellaroli. São Paulo: Companhia das Letras, 2006.

BACHMANN-MEDICK, Doris. Cultural Turns. Neuorientierungen in den Kulturwissenschaften. Reinbek bei Hamburg: Rowohlt, 2006.

CASTRO RICALDE, Maricruz. Las narraciones de Julia Álvarez: hibridez y contexto multicultural. Revista Brasileira do Caribe, v. VI, no. 11, p. 209-235, 2005.

MATIAS-FERREIRA JR., Tito. A diáspora hispano-caribenha na ficção de Julia Alvarez: mediações entre culturas, línguas e geografias. Cadernos do IL, n. 45, p. 109-122, 2012.

HALLET, Wolfgang; NEUMANN, Birgit. Raum und Bewegung in der Literatur: Zur Einführung. In: HALLET, Wolfgang; NEUMANN, Birgit (eds.). Raum und Bewegung in der Literatur. Die Literaturwissenschaften und der Spatial Turn. Bielefeld: Transcript Verlag, 2009, p. 11-32.

MATHIAS, Dionei. Literatura e fluxos migratórios em contextos anglófonos: sobre a gênese discursiva de um campo de pesquisa. Scripta Uniandrade, v. 16, p. 225-238, 2018.

MATHIAS, Dionei. Alteridade e infância no conto 'We're not Jews' de Hanif Kureishi. Revell Revista de Estudos Literários da UEMS, v. 4, p. 66-81, 2020.

MATHIAS, Dionei. Mães e filhas em Oscar Hijuelos e Junot Díaz. Revista de Letras Norte@ mentos, v. 14, p. 180-192, 2021.

MEDINA, Manuel F. Writing from memory: history, stories and narrative voices in In the Time of the Butterflies by Julia Álvarez. Ilha do Desterro, n. 59, p. 147-161, 2010. 